\title{
Development and validation of a new global well-being outcomes rating scale for integrative medicine research Iris R Bell*1,2,3,4,5,6, Victoria Cunningham ${ }^{1,3}$, Opher Caspi ${ }^{1,3,4}$, Paula Meek ${ }^{7}$ and Lynn Ferro ${ }^{1}$
}

\begin{abstract}
Address: ${ }^{1}$ Program in Integrative Medicine, The University of Arizona College of Medicine, Tucson, AZ, USA, ${ }^{2}$ Department of Psychiatry, The University of Arizona College of Medicine, Tucson, AZ, USA, ${ }^{3}$ Department of Psychology, The University of Arizona, Tucson, AZ, USA, ${ }^{4}$ Department of Medicine, The University of Arizona College of Medicine, Tucson, AZ, USA, ${ }^{5}$ Department of Surgery, The University of Arizona College of Medicine, Tucson, AZ, USA, ${ }^{6} \mathrm{Mel}$ and Enid Zuckerman Arizona College of Public Health, The University of Arizona, Tucson, AZ, USA and ${ }^{7}$ College of Nursing, The University of New Mexico Health Sciences Center, Albuquerque, NM, USA
\end{abstract}

Email: Iris R Bell* - ibell@u.arizona.edu; Victoria Cunningham - vickic@email.arizona.edu; Opher Caspi - ocaspi@ahsc.arizona.edu; Paula Meek - pmeek@salud.unm.edu; Lynn Ferro-mferro@email.arizona.edu

* Corresponding author

Published: 15 January 2004

BMC Complementary and Alternative Medicine 2004, 4:1
Received: 03 September 2003

Accepted: 15 January 2004

This article is available from: http://www.biomedcentral.com/l472-6882/4/I

(C) 2004 Bell et al; licensee BioMed Central Ltd. This is an Open Access article: verbatim copying and redistribution of this article are permitted in all media for any purpose, provided this notice is preserved along with the article's original URL.

\begin{abstract}
Background: Researchers are finding limitations of currently available disease-focused questionnaire tools for outcome studies in complementary and alternative medicine/integrative medicine (CAM/IM).

Methods: Three substudies investigated the new one-item visual analogue Arizona Integrative Outcomes Scale (AIOS), which assesses self-rated global sense of spiritual, social, mental, emotional, and physical well-being over the past 24 hours and the past month. The first study tested the scale's ability to discriminate unhealthy individuals $(n=50)$ from healthy individuals $(n=50)$ in a rehabilitation outpatient clinic sample. The second study examined the concurrent validity of the AIOS by comparing ratings of global well-being to degree of psychological distress as measured by the Brief Symptom Inventory (BSI) in undergraduate college students $(N=458)$. The third study evaluated the relationships between the AIOS and positively- and negatively-valenced tools (Positive and Negative Affect Scale and the Positive States of Mind Scale) in a different sample of undergraduate students $(N=62)$.

Results: Substudy (i) Rehabilitation patients scored significantly lower than the healthy controls on both forms of the AIOS and a current global health rating. The AIOS 24-hours correlated moderately and significantly with global health (patients $r=0.50$; controls $r=0.45$ ). AIOS I-month correlations with global health were stronger within the controls (patients $r=0.36$; controls $r=0.50$ ). Controls $(r=0.64)$ had a higher correlation between the AIOS 24-hour and Imonth forms than did the patients $(r=0.33)$, which is consistent with the presumptive improvement in the patients' condition over the previous 30 days in rehabilitation. Substudy (ii) In undergraduate students, AIOS scores were inversely related to distress ratings, as measured by the global severity index on the BSI $\left(r_{\text {AIOS24h }}=-0.42, r_{\text {AIOSImonth }}=-0.40\right)$. Substudy (iii) AIOS scores were significantly correlated with positive affect $\left(r_{\text {AlOS24h }}=0.56, r_{\text {AIOSImonth }}=0.57\right)$ and positive states of mind $\left(r_{\mathrm{AIOS} 24 \mathrm{~h}}=0.42, \mathrm{r}_{\mathrm{AIOS} \text { Imonth }}=0.45\right)$, and inversely correlated with negative affect $\left(\mathrm{r}_{\mathrm{AIOS} 24 \mathrm{~h}}=-0.4 \mathrm{I}, \mathrm{r}_{\mathrm{AIOSI} \text { month }}\right.$ $=-0.59)$.
\end{abstract}


Conclusions: The AIOS is able to distinguish relatively sicker from relatively healthier individuals; and correlates in expected directions with a measure of distress and indicators of positive and negative affect and positive states of mind. The AIOS offers a tool for CAM/IM research that extends beyond a disease emphasis.

\section{Background}

The field of complementary and alternative medicine (CAM)/integrative medicine (IM) (CAM/IM) has grown substantially in recent years $[1,2]$. Consumer utilization rates in the U.S. have reached over $40 \%$ [1]. Together with the extensive use of CAM by the general population, research activity, clinical services, and medical education programs in this area are also on the rise. Clinical claims of many CAM providers from different disciplines converge on their concern with individually-salient quality of life outcomes as primary, and conventional medical disease endpoints as secondary, in assessing benefit: risk ratios [3-6]. Issues that matter to one person may have little relevance to another. Moreover, many CAM modalities address the full scope of a person's life, including spiritual, mental, emotional, and physical outcomes, rather than limiting themselves to "health-related" quality of life or physical disease [7].

Investigators have initially attempted to adapt tools from conventional quality of life research, e.g., the SF-36 [8], but these standardized measures limit their scope to preselected functional aspects of physical and emotional health. Furthermore, the SF-36 may be better at differentiating sick from healthy people than in assessing degrees of illness or levels of wellness [9]. The domain of CAM outcomes includes not only disease and absence of disease as in conventional medical research, but also levels of wellness [6]. This philosophical orientation overlaps with the World Health Organization's (WHO) definition of health as: "Health is not only the absence of infirmity and disease, but also a state of physical, mental, and social wellbeing" $\quad$ http://www.who.int/aboutwho/en/defini tion.html. Ideally, outcome measures for any type of health care, CAM/IM or conventional, should capture the full scope and integration of global well-being status.

Measures such as the Functional Assessment of Chronic Illness Therapies (FACIT) offer some advantage over the SF-36 in that the FACIT includes a module on spirituality $[10,11]$. Even the FACIT, however, highlights coping with chronic disease rather than optimizing well-being. Many persons report their use of CAM as a preventive rather than treatment strategy [12]; thus, evaluating their outcomes requires determination of change not only in negative, but also positive, areas of life. Positive subscales from the Positive and Negative Affect Scale [13] and the Positive States of Mind Scale [14,15] may address some of these mental and emotional outcomes.
In addition to these multi-item measures, researchers and clinicians in CAM/IM and conventional medicine need global rating scales for providers and patients that are better tailored to the full picture of purported clinical outcomes. A brief subjective scale, amenable to multiple ratings over extended periods of time, permits minimallyburdensome tracking of day-to-day or month-to-month change in overall well-being. The Arizona Integrative Outcomes Scale (AIOS) was developed as a first step in a program of developing and validating a set of outcome measures for research on CAM/IM care [6]. This simple scale also offers the possibility of clinical applications in tracking treatment progress.

\section{Methods}

The Arizona Integrative Outcomes Scale (AIOS) is a oneitem, visual analogue self-rating scale (VAS) with two alternate forms (one for daily ratings, AIOS-24h; and one for monthly ratings, AIOS- $1 \mathrm{~m}$ )( see Additional file: 1 ). The instructions are: "Please reflect on your sense of wellbeing, taking into account your physical, mental, emotional, social, and spiritual condition over the past 24 hours [over the past month]. Use an X on the line to mark your answer to the question. Mark the line below with an $\mathrm{X}$ at the point that summarizes your overall sense of wellbeing for the past 24 hours [for the entire month]." The horizontally-displayed VAS is $100 \mathrm{~mm}$ in length, with the low anchor being, "Worst you have ever been" and the high anchor being, "Best you have ever been." We evaluated the AIOS against various other measures in three substudies, all of which were reviewed and approved by the University of Arizona Institutional Review Board.

\section{SUBSTUDY I: CLINICAL SAMPLE: AIOS, Global Health, and Clinical Status Measures}

The goal of this substudy was to evaluate the concurrent validity of the AIOS. Trochim [16] defines concurrent validity as an instrument's ability to distinguish between groups that it should theoretically be able to distinguish. Hence, this study focused on patients in an outpatient rehabilitation clinic and their caregivers, visitors, and staff. A secondary rationale for using a rehabilitation patient population was the likelihood that they would have been in process of change over the previous month, thereby permitting some comparison of the 24-hour and 1 -month forms (concomitantly completed) as a cross-sectional indicator of sensitivity to change. We determined the relationship of the AIOS well-being ratings to partici- 
pants' current medical status and prescription medication use, as well as ratings of global physical health.

\section{Subjects and Procedures}

Data were collected on 100 subjects using a convenience sampling methodology. Since one of the aims of this study was to determine whether the AIOS could distinguish between relatively unhealthy people and relatively healthy people, the sample was purposefully split into two groups, unhealthy subjects (registered patients, both inpatient or outpatient) $(\mathrm{n}=50)$ and relatively healthy subjects (caregiver controls, who were either clinic staff or those visiting or accompanying the registered patients) (n $=50)$.

The present research was conducted in a rehabilitation hospital located in a large southwestern city (Tucson, AZ). Permission was granted from the clinic coordinator to approach registered patients, visitors and clinic staff for the current study. During the ten-month period from August 2000, to May 2001, a member of the study team made weekly visits to the clinic to elicit participation from potential subjects. Participants were required to be English-speaking, cognitively-intact persons who were at least 18 years of age. Individuals who gave consent to participate were asked to fill out a short questionnaire that focused on their global well-being and health status. Before proceeding, researchers ensured that subjects understood the instructions. Total in-person time with the subjects was approximately 10 minutes. After completing the questionnaire, research staff thanked subjects for their participation and answered any questions they had about the nature of the research.

\section{Measures \\ Clinical information}

In addition to completing the two forms of the AIOS, all subjects reported their age, gender, any medical diagnoses, co-morbidities [17] and current prescription medications. Registered patients' medical diagnoses, number of co-morbidities, and current prescription medications self-reported information were checked for accuracy against their medical records with their permission.

\section{Overall physical health status}

Single-item global health ratings have demonstrated consistently to be meaningful indicators of mortality and have better predictive validity for mortality and physical disease outcomes than physician ratings [18-23]. Using a Likert-type five-point scale where 1 is 'poor' and 5 is 'excellent', respondents were asked to rate their overall physical health 'right now.'

\section{Statistical analysis}

Analysis of covariance, controlling for age, was conducted in order to detect differences between rehabilitation patients and healthy caregivers on the AIOS, the global health rating, number of co-morbidities, and current prescription medications. Chi-square analyses were used to examine differences between groups for gender. Paired ttests were used to compare scores within each group for the two different time frames of the AIOS. Concurrent validity of the AIOS was examined by means of calculating Pearson correlation coefficients between the AIOS and the global physical health rating within each group and across all subjects. The global health rating served as a criterion variable (e.g., poorer ratings of overall physical health should correlate negatively with higher ratings of global well-being on the AIOS).

\section{Results}

\section{Sample characteristics}

Both groups were similar in gender (62\% (31/50) patients were women; and 52\% (26/50) caregivers were women). However, there were significant differences between the two groups with respect to age (mean age of patients $=65.0, \mathrm{SD} 14.7$; mean age of caregivers $=49.8, \mathrm{SD}$ 17.3: $\mathrm{t}(97)=-4.7, \mathrm{p}<0.001)$. Consequently, age was controlled for in all between-group analyses. The majority of patients had no other illnesses $(n=23 ; 46 \%), 14$ others reported at least one other co-morbidity, and 13 others had more than one, but no more than four health conditions. Fifty-four percent of the caregivers reported no comorbidities $(n=32), 14$ reported at least one other health condition, and four reported more than one, but no more than four. A chi-square test of independence was performed to examine the relationship between number of co-morbidities and group membership. Results indicate a non-significant relationship between these variables, X2 $(8, \mathrm{~N}=100)=11.97, \mathrm{p}=0.15$. Although patients overall had more co-morbid conditions, they were no more likely to have substantially more conditions than their healthy counterparts. The majority of patients were in rehabilitation for musculoskeletal reasons (76\%), followed by stroke rehabilitation $(12 \%)$ and other miscellaneous conditions (16\%) (e.g., post-myocardial infarction, pneumonia). One-way analysis of variance revealed significant between-group differences in the average number of current prescription medications (mean for patient group = 4.2 SD 3.1; mean for caregivers $=1.0$ SD 1.6: F1.97 $=42.1$, $\mathrm{p}<0.001)$. Within the caregiver group, those who were visitors did not differ on the outcome variables from those who were facility staff members.

\section{Scale validity}

Table 1 displays mean scores for the scales. An analysis of variance controlling for age revealed that patients reported significantly lower global well-being and overall 
Table I: Mean Scores for AIOS and Global Health Scale.

\begin{tabular}{lcc}
\hline & Patients $(\mathrm{n}=50)$ & Caregivers $(\mathrm{n}=50)$ \\
\hline Global Well-Being & & \\
AIOS-24h* $(0-100 \mathrm{~mm})$ & $50.30(23.17)$ & $65.20(19.50)$ \\
AIOS-I m* $(0-100 \mathrm{~mm})$ & $32.53(23.77)$ & $60.58(20.36)$ \\
Current Global Health* $(\mathrm{I}-5)$ & $2.96(1.12)$ & $3.80(0.81)$ \\
\hline
\end{tabular}

* between group significantly different at $\mathrm{p}<0.007$.

Table 2: Pearson Correlation Coefficients between AIOS Ratings, Global Health Rating, and Clinical Variables.

\begin{tabular}{|c|c|c|c|c|c|c|}
\hline \multirow[b]{2}{*}{ Measures } & \multicolumn{2}{|c|}{ Patients $(\mathrm{n}=50)$} & \multicolumn{2}{|c|}{ Caregivers $(n=50)$} & \multicolumn{2}{|c|}{ Total Sample $(n=100)$} \\
\hline & AlOS24h & AIOSIm & AlOS24h & AlOSIm & AlOS24h & AIOSIm \\
\hline AIOS-24h & --- & & --- & & --- & \\
\hline AIOS-Im & $0.33^{*}$ & --- & $0.64 * *$ & --- & $0.52^{*}$ & --- \\
\hline Global Current Health & $0.49 * *$ & $0.36^{*}$ & $0.45^{* *}$ & $0.50 * *$ & $0.53^{*}$ & $0.53^{*}$ \\
\hline \# co-morbidities & -0.05 & -0.25 & -0.01 & -0.04 & -0.11 & $-0.29 *$ \\
\hline \# medications & 0.05 & $-0.40 * *$ & 0.01 & 0.04 & 0.13 & $-0.48^{*}$ \\
\hline
\end{tabular}

$*_{p}<0.02,{ }^{*} \mathrm{p}<0.001$

physical health status than did caregivers $\left(\mathrm{F}_{2,98}=5.0, \mathrm{p}<\right.$ $0.01)$. Paired t-tests revealed that scores on the AIOS-24h were significantly different from those on the AIOS- $1 \mathrm{~m}$ within the patient group $(\mathrm{t}(48)=4.8, \mathrm{p}=0.001)$ but not within the caregiver group.

Table 2 summarizes the correlation coefficients for the primary variables by group and across all participants. For patients, the AIOS-24h and AIOS- $1 \mathrm{~m}$ correlated significantly with each other, and with ratings of current physical health, but neither correlated with the number of comorbid conditions. AIOS- $1 \mathrm{~m}$, but not AIOS-24h, correlated significantly with the number of prescription medications in the patient group. The caregivers also demonstrated significant correlations between their AIOS-24h and AIOS- $1 \mathrm{~m}$ scores and the global health rating. Neither of the two AIOS scales revealed significant associations with number of comorbidities or with number of prescription medications in the caregiver group.

Finally, correlations of AIOS-24h and AIOS- $1 \mathrm{~m}$ were significantly different between the two groups (patients $\mathrm{r}=$ 0.33 ; caregivers $\mathrm{r}=0.64 ; \mathrm{t}=-2.01, \mathrm{p}=0.02$ ). The latter observation suggests that caregivers' perceived their wellbeing more similarly for both time frames than did the rehabilitation patients.

\section{SUBSTUDY 2: UNIVERSITY STUDENT SAMPLE: AIOS, Global Health and Distress Ratings}

The purpose of this substudy was to examine the convergent validity of the AIOS by comparing it with self-report measures of global physical health status and selfreported psychological distress in young, healthy persons. We hypothesized that better global well-being, as indicated by higher AIOS scores, would be associated with less psychological distress, as indicated by lower scores on the Brief Symptom Inventory (BSI)[24].

\section{Subjects and Procedures}

A total of 458 undergraduate college students enrolled in an introductory level psychology course at the University of Arizona completed a set of questionnaires detailed below as part of a larger mass survey. As such, students were assumed to understand instructions associated with our questionnaires. The sample included 188 males with a mean age of 18.9 SD 1.8 and 270 females with a mean age of 19.2 SD 3.6.

\section{Measures \\ Global Well-being and Global Physical Health}

As in Substudy 1, subjects completed the AIOS and the Global Current Health Rating Scale.

\section{Psychological Distress}

Psychological distress was measured by the well-validated Brief Symptom Inventory [24]. Respondents are asked to 
Table 3: Means Scores (S.D.) for AIOS, Global Health Ratings, and BSI GSI for Psychologically Distressed and Non-Distressed Students.

\begin{tabular}{|c|c|c|c|}
\hline Scale & Total Sample & T GSI > $63(n=58)$ & T GSI $<63(n=400)$ \\
\hline & Mean (S.D.) & Mean (S.D.) & Mean (S.D.) \\
\hline \multicolumn{4}{|l|}{ Global Well-being } \\
\hline AIOS-24h & $64.3(18.1)$ & $52.2(19.9)$ & $66.1(17.2)$ \\
\hline AIOS-Im & $65.8(19.7)$ & $51.2(21.6)$ & $67.9(18.5)$ \\
\hline Global Current Health & $3.8(0.9)$ & $3.5(1.1)$ & $3.8(0.9)$ \\
\hline \multicolumn{4}{|l|}{ BSI Psychological Distress } \\
\hline GSI & $56.2(6.6)$ & $70.6(5.4)$ & $54.2(3.4)$ \\
\hline
\end{tabular}

*Note that the Global Severity Index is reported as a T-score.

rate 53 items about how distressed s/he felt on a variety of symptoms "over the past week, including today" using a five-point scale (0-4) anchored at one end by not at all (0) to extremely (4) at the other end. The BSI yields nine primary symptom dimensions and three global indices of distress. One of these global indices, the global severity index (GSI), is considered to be the single best predictor of a respondent's level of psychological distress and was therefore the only subscale used for analysis in this study. Test-retest reliability for the GSI of 0.90 has shown the instrument to be stable [25].

\section{CAM use}

The following single-item yes/no question was included: "Do you currently use, or have you ever used, alternative forms of medicine (i.e., herbs, massage, acupuncture, etc.)?"

\section{Statistical analysis}

Data analyses used were independent sample t-tests, chisquare analyses and linear regression analysis.

\section{Results}

Means and standard deviations for each of the scales are presented in Table 3. Cronbach's alpha for the BSI in this sample was 0.97. Scores on the BSI in this sample were comparable to previously established college student norms [25].

According to Derogatis [26], psychological distress is indicated by T-scores 63 or above on the GSI. Thirteen percent of the 458 participants $(n=58)$ scored greater than 63 for their T-score of their GSI, slightly higher than the $10 \%$ observed in population controls. Psychologically distressed students reported significantly lower scores than non-distressed students on the AIOS-24h $(\mathrm{t}(456)=5.6, \mathrm{p}$ $<0.001)$; AIOS- $1 \mathrm{~m}(\mathrm{t}(456)=6.3, \mathrm{p}<0.001)$; and selfrated current health $(\mathrm{t}(456)=-2.5, \mathrm{p}<0.01)$. Psychologically distressed participants were no different in their use of CAM from non-distressed individuals $\left(\mathrm{X}^{2}(1, \mathrm{~N}=456)=\right.$ $0.47, \mathrm{p}=0.49$ ).

Table 4 shows correlation coefficients between the AIOS and each the study variables. Each version of the AIOS (past 24 hours and 1 month) correlated positively with the global health rating. Convergent validity was supported by the significant relationship between higher levels of global well-being and lower scores of psychological distress on the BSI global severity index. Spearman correlation coefficients revealed a negligible association between CAM use and global well-being AIOS ratings.

Although CAM use was weakly associated with ratings of poorer overall physical current health, it was not correlated with lower ratings of global well-being as measured by the AIOS. Poorer overall physical health status also correlated negatively with BSI global severity index. Conversely, better physical health status was associated with higher ratings of global well-being for both the past 24 hours and the past 30 days.

A simultaneous regression analysis was conducted using BSI T-GSI and current self-rated global health as independent variables to explain variance in AIOS ratings. Although the overall model was significant $\left(\underline{\mathrm{F}}_{4,455}=75.89\right.$, $\mathrm{p}<0.001)$, the amount of variance that was explained in the AIOS-24h ratings was fair $\left(\underline{\mathrm{R}}^{2}{ }_{\mathrm{ADI}}=25 \%\right)$. AIOS- $24 \mathrm{~h}$ scores were negatively related to psychological distress (B $=-0.09)$ and positively related to current global health status $(B=5.7)$. Both variables were significantly different from zero (BSI T-GSI: $\underline{\mathrm{t}}(455)=-8.0, \mathrm{p}<0.001$; current health status; $\underline{\mathrm{t}}(455)=7.0, \underline{\mathrm{p}}<0.001)$.

The same model was run for AIOS-1m scores. The overall model was significant $\left(\underline{\mathrm{F}}_{4,455}=65.8, \mathrm{p}<0.001\right)$ and explained slightly less variance than for the AIOS-24h ratings $\left(\underline{R}^{2}{ }_{A D I}=22 \%\right)$. AIOS $-1 \mathrm{~m}$ scores were negatively related to psychological distress $(B=-1.0)$ and positively related to current health status $(B=5.5)$. Both variables 
Table 4: Correlations between AIOS and Other Measures in University Students $(\mathbf{N}=\mathbf{4 5 8})$.

\begin{tabular}{lccccc}
\hline & AIOS-24h & AIOS-Im & Global Current Health & BSI GSI & CAM Use \\
\hline AIOS-24h & --- & $0.7 I^{*}$ & $0.38^{*}$ & $-0.4 I^{*}$ & -0.07 \\
AIOS-Im & & --- & $0.34^{*}$ & $-0.40^{*}$ & -0.07 \\
\hline
\end{tabular}

$* p<0.01$

were significantly different from zero (T-GSI: $\underline{\mathrm{t}}(455)=-$ 8.0, $\mathrm{p}<0.001$; current health status: $\mathrm{t}(455)=6.0, \mathrm{p}<$ $0.001)$.

\section{SUBSTUDY 3: UNIVERSITY STUDENT SAMPLE: AIOS, Positive and Negative Mood, Positive States of Mind Ratings}

Based on the results from the previous substudies, this substudy was conducted to explore the extent of additional variance in AIOS scores that positive dimensions could explain in a healthy population. Previous research has focused on variables measuring negative dimensions and has concluded that lack of negative experiences or reported symptoms are associated with better states of overall well-being. In order for the AIOS to be considered a useful and unique addition to outcome tools currently available, it must provide a more complete picture of factors that contribute to global well-being. Thus, we hypothesized that the AIOS not only would be inversely correlated with measures of negative affect and psychological distress, but also positively correlated with measures of positive affect and states of mind dimensions.

\section{Subjects and Procedures}

Sixty-two undergraduate college students enrolled in an international studies course at the University of Arizona completed the AIOS and other instruments, with an instructor available to help answer any questions.

\section{Measures}

Positive and Negative Affect Scales (PANAS)

The PANAS is a 20-item questionnaire designed to measure positive and negative affect with little overlap [13]. Subjects are instructed to rate each item on a 5-point scale reflecting the extent to which they experienced the emotion during the past 24 hours. The scale for each item ranges from 0 (very slightly or not at all) to 4 (extremely). The two subscales have been demonstrated to have sound psychometric properties. Higher positive affect scores correlate with better perceived CAM effectiveness in patients with chronic pain or cancer [27].

\section{Positive States of Mind Scale (PSOMS)}

The PSOMS was included based on findings that positive states of mind have been shown associated with better general perceptions of health [15]. This measure is designed to detect subtle changes in the ability to achieve and appreciate positive experiences. It provides a discrete measure of seven specific states (including focused attention, productivity, sharing, responsible caretaking, restful repose, sensuous nonsexual and sexual pleasure) as a summation of the individual's ability to achieve each of these positive states of mind within the last 7 days. The response categories used to rate each state range from 0 to 3 where 0 represents an inability to achieve the state and 3 represents full attainment. Cronbach's alpha has been reported at 0.65 in a university sample [15].

\section{Results}

Descriptive statistics for this sample are provided in Table 5. Overall AIOS and global current health were somewhat lower in this sample, while psychological distress was greater in this sample as compared with students from Substudy 2.

Correlations between the AIOS and the global current health rating, BSI GSI, PANAS, and PSOMS are presented in Table 6. The data support our hypothesis that the AIOS scale would be positively related with both the PSOMS and the positive subscale of the PANAS. We also found evidence to support our other prediction that higher AIOS scores signifying greater overall well-being would be inversely related with negative affect and greater psychological distress. Only the AIOS-24h version was significantly associated with ratings of current overall global physical health status.

Variables were selected as candidates for a simultaneous regression analysis based on the level of significance of the bivariate association with the dependent variable. The total amount of variance explained in AIOS-24h scores was approximately 37\% (adjusted $\left.\mathrm{R}^{2}\right)\left(\underline{\mathrm{F}}_{5,53}=7.8, \mathrm{p}<\right.$ $0.001)$. For this sample, the positive pole of the PANAS was a significant predictor $(B=1.04, \mathrm{p}<0.007)$. Psychological distress on the BSI global severity index was marginally significant $(\mathrm{B}=-10.7, \mathrm{p}<0.06)$. Analyzing the AIOS- $1 \mathrm{~m}$ ratings yielded slightly different result, but was still an overall significant model explaining $57 \%$ of the variance $\left(\mathrm{F}_{5,48}=12.6, \mathrm{p}<0.001\right)$. Both the positive and negative poles of the PANAS were the only significant pre- 
Table 5: Mean (S.D.) and Range for All Scales (N = 62).

\begin{tabular}{lcc}
\hline & Mean (S.D.) & Range \\
\hline Global Well-Being & & $13-98$ \\
$\quad$ AIOS-24h & $57.61(22.07)$ & $0-98$ \\
AIOS-Im & $53.82(23.81)$ & $1-5$ \\
Global Current Health & $3.23(1.02)$ & $50.2-80.0$ \\
BSI Psychological Distress & $58.7(6.7)$ & $16-50$ \\
$\quad$ GSI & $3.62(7.91)$ & $10-42$ \\
PANAS & $2.66(6.85)$ & $3-21$ \\
$\quad$ Positive dimension & $14.77(4.25)$ & \\
$\quad$ Negative dimension & & \\
PSOMS & & \\
\hline
\end{tabular}

Note: GSI (Global Severity Index) are reported as T-scores, PANAS = Positive and Negative Affect Scale, PSOMS = Positive States of Mind Scale.

Table 6: Correlations between the AIOS and Measures of Global Health Ratings, Psychological Distress, Positive Affect, Negative Affect, and Positive States of Mind ( $\mathbf{N}=62)$.

\begin{tabular}{lccccccc}
\hline & AIOS-24h & AIOS-Im & GCH & BSI GSI & PANAS - PA & PANAS - NA & PSOMS \\
\hline AIOS-24h & -- & $0.65^{* *}$ & $0.26^{*}$ & $-0.58^{* *}$ & $0.56^{* *}$ & $-0.41^{* *}$ & $0.42^{* *}$ \\
AIOS-Im & -- & 0.22 & $-0.62^{* *}$ & $0.57^{* *}$ & $-0.59^{* *}$ & $0.45^{* *}$
\end{tabular}

Note: GCH is Global Current Health; BSI GSI is Brief Symptom Inventory Global Severity Index; PANAS - PA is Positive Affect subscale of PANAS, PANAS - NA is Negative Affect subscale of PANAS; PSOMS is Positive States of Mind Scale. ${ }^{*} p<.005,{ }^{* *} p<0.01$

dictors $(\mathrm{B}=1.06, \mathrm{p}<0.007, \mathrm{~B}=-1.46, \mathrm{p}<0.003$ respectively).

\section{Discussion}

The AIOS is a simple visual analogue scale useful for assessing global well-being in both research and clinical samples. The scale is quick to administer in both clinically-ill and non-clinical healthy populations. Future studies need to examine the acceptability and feasibility of using the AIOS, given the possibility that some populations may experience difficulty comprehending the instructions for completing a visual analogue scale format. Taken together, the present findings indicate that the AIOS captures not only less self-perceived disease and negative mood, but also greater physical health and positive dimensions of mental and emotional states. As a single item, the AIOS could lend itself to repeated measure or time-series analyses for examining patterns over time for documenting natural history and CAM/IM treatment responses within a wide range of conditions [28,29]. Establishing temporal stability of the AIOS via test-retest reliability would be useful when constructs such as wellbeing are hypothesized to remain relatively stable across time. However, shifts in levels of well-being that can be attributed to treatment effects would yield weak test-retest reliability estimates. Therefore, depending on the intended use of the AIOS, either high or low test-retest reliability would be expected.

In Substudy 1, the AIOS distinguished rehabilitation outpatients with mixed diagnoses from caregiver controls at the same facility. The cross-sectional data also reveal convergent findings that suggest using the two different timeframe forms of the AIOS may detect fluctuations or shifts in condition. That is, the correlation coefficient for the 24hour and 1-month forms was significantly greater among caregivers than patients. Moreover, only the AIOS-1m score for patients correlated with the number of prescription medications. Such findings would be consistent with the expected change toward improved health and wellbeing in the patients in rehabilitation treatment, but not the controls, over the course of the previous month. Patients may have begun the month more ill and needing more medications, but their current sense of their overall well-being was greater than it was one month ago. Prospective research is needed to confirm these types of changes over time in rehabilitation patients and other clinical and non-clinical populations.

Previous research has shown that spouse caregivers of seriously ill persons suffer from subclinical to clinical depression at increased rates [30]. The caregiver sample in this study was not chosen to reflect idealized mental, emo- 
tional, or physical health; they simply were not patients at the facility. For discriminant validity, it was important to demonstrate that the AIOS could differentiate varying degrees, rather than only extremes, of health status. The data available in this study do not permit detailed comprehensive evaluation of the component domains of the well-being item, i.e., spiritual, social, mental, emotional, and physical. Additional health outcomes research should focus on developing systematic approaches to identifying these types of individualized needs and preferences and implementing the most appropriate, complementary interventions, which together may improve overall wellbeing and facilitate achieving very high scores on the AIOS.

A number of prospective studies suggest that self-rated global health status is a better predictor of not only mortality, but also health care utilization, than are more "objective" clinical laboratory data, physician examinations, or professional assessments $[18,19,31,32]$. Thus, while Substudy 1 limitations include a lack of laboratory data correlations, the availability of the global health ratings and chart lists of co-morbidities and medications enrich interpretation of the meaning of the AIOS self-ratings.

The AIOS scores for the relatively healthy caregiver controls from Substudy 1 and the college students from Substudies 2 and 3 demonstrate that these individuals were far from optimal in well-being (mean scores around 60 out of a possible $100 \mathrm{~mm}$ ). The lack of ceiling effects for non-patients in the present study is encouraging for using the AIOS in CAM/IM outcome and prevention studies outside clinical settings. That is, the scale allows the potential for a major degree of improvement in self-rated well-being above and beyond the relative lack of diagnosed health problems.

As intended, data from Substudies 2 and 3 indicate that the AIOS captures domains other than just global physical health. The correlations between both AIOS forms and the global current health rating were only moderate, not high, in patients, caregivers, and college students. In addition to physical health, lower levels of psychological distress as well as higher levels of positive mood were especially associated with better AIOS self-ratings in young adult college students. The small differences on well-being, health, and distress ratings between the Substudy 2 and 3 college students may relate, in part, to sampling from different members of the overall university population (e.g., issues stemming from university plans to phase out the program in which those in Substudy 3 were enrolled).

It will be important to extend this research to specific patient groups, including those with major psychiatric problems or with various homogeneous chronic disease diagnoses, studied over periods of months. The possible correlations between the AIOS variable of global wellbeing and standardized measures of quality of life and of health care satisfaction merit investigation. It may be instructive to examine the relative amounts of variance in AIOS self-ratings for which scores on standardized instruments covering each of the separate spiritual, social, mental, emotional and physical domains account $[10,11,33]$.

\section{Conclusions}

The purpose of these studies was to validate a visual analogue rating scale for global well-being, to use in outcomes research on diverse patient and non-patient populations. This type of scale avoids the pitfall of presuming how each individual may weight the importance of specific items or functions for him/herself on a quality of life scale. Moreover, during CAM/IM treatment, even some persons with terminal medical conditions and severe physical disability nonetheless report achieving a high level of life satisfaction and general sense of wellbeing. Physically-disabled patients report CAM/IM use at higher rates than do the general population [34]. The AIOS provides a means for simple, quick assessment of well-being for daily or monthly use. The next step will be to evaluate the sensitivity of the AIOS to change in prospective studies.

\section{List of Abbreviations}

CAM/IM or CAIM complementary and alternative medicine/integrative medicine

AIOS Arizona Integrative Outcomes Scale $(24 \mathrm{~h}=24$-hour form; $1 \mathrm{~m}=1$-month form)

BSI Brief Symptom Inventory

GSI Global Severity Index of the Brief Symptom Inventory

PANAS Positive and Negative Affect Schedule

PSOMS Positive States of Mind Scale

SF-36 Short Form (36 item) of the Medical Outcomes Scale

FACIT Functional Assessment of Chronic Illness Treatment Scale

SD Standard Deviation

VAS Visual Analogue Scale

B Standardized beta weights 


\section{Competing Interests}

None declared.

\section{Authors' Contributions}

IRB developed the AIOS scale and designed the validation substudies in collaboration with VC, OC, PM, and LF. VC and LF developed and implemented the study data collection and management protocol. OC coordinated Substudy 1. PM served as a consultant regarding the psychometric and statistical analyses, which VC performed. All authors contributed to and reviewed the final manuscript.

\section{Additional material}

\section{Additional file 1}

Click here for file

[http://www.biomedcentral.com/content/supplementary/14726882-4-1-S1.doc]

\section{Acknowledgments}

The authors thank Health South Rehabilitation Center, Tucson, AZ, for allowing access to their facility in performing this study. This study was supported in part by NIH grants K24 AT00057 (IRB), R2I AT003 I 5 (IRB), and P50 AT00008. Its contents are solely the responsibility of the authors and do not necessarily represent the official views of NCCAM or NIH. The findings were presented in part at the International Scientific Conference on Complementary, Alternative, and Integrative Medicine Research, San Francisco, CA, May 17-19, 2001.

\section{References}

I. Eisenberg D.M., Davis, R.B., Ettner, S.L., Appel, S., Wilkey, S., Van Rompay, M., Kessler, R.C.: Trends in alternative medicine use in the US, 1990-1997. Results of a follow-up national survey. JAMA 1998, 280:I569-1575.

2. Astin JA: Why patients use alternative medicine: results of a national study.[comment]. Jama. 1998, 279:1548-1553.

3. Gould A., MacPherson, $H$.: Patient perspectives on outcomes after treatment with acupuncture. Journal of Alternative and Complementary Medicine 200I, 7:261-268.

4. Paterson C., Britten, N.: In pursuit of patient-centred outcomes: a qualitative evaluation of MYMOP, MeasureYourself Medical Outcome Profile. Journal of Health Services Research \& Policy 2000, 5:27-36.

5. Paterson C: Measuring outcome in primary care: a patientgenerated measure, MYMOP, compared to the SF-36 health survey. $B M$ J 1996, 3 I 2:1016-1020.

6. Bell IR, Caspi O, Schwartz GE, Grant KL, Gaudet TW, Rychener D, Maizes V, Weil A: Integrative medicine and systemic outcomes research: issues in the emergence of a new model for primary health care. Archives of Internal Medicine. 2002, 162:133-140.

7. Jonas W.B., Levin, J.S.: Essentials of Complementary and Alternative Medicine. Philadelphia, Lippincott Williams and Wilkins; 1999.

8. Ware J.E., Sherbourne, C.D.: The MOS 36-item short-form health survey (SF-36). Medical Care 1992, 30:473-483.

9. Kane RL: Understanding Health Care Outcomes Research. Gaithersburg, MD, Aspen; 1997.

10. Cella $D$, Nowinski $C$ J: Measuring quality of life in chronic illness: the functional assessment of chronic illness therapy measurement system. Archives of Physical Medicine \& Rehabilitation. 2002, 83:SI0-7.
II. Peterman Amy H., Fitchett George, Brady Marianne J., Hernandez Lesbia, Cella David: Measuring spiritual well-being in people with cancer: The Functional Assessment of Chronic IIlness Therapy-Spiritual Well-Being Scale (FACIT-Sp). Annals of Behavioral Medicine 2002, 24:49-58.

12. Baldwin CM, Long K, Kroesen K, Brooks AJ, Bell IR: A profile of military veterans in the southwestern United States who use complementary and alternative medicine: implications for integrated care. Archives of Internal Medicine. 2002, 162:1697-1704.

13. Watson D., Clark, L.A., Tellegen, A.: Development and validation of brief measures of positive and negative affect: the PANAS scales. Journal of Personality and Social Psychology 1988, 54:1063-1070.

14. Horowitz M., Adler, N., Kegeles, S.: A scale for measuring the occurrence of positive states of mind: a preliminary report. Psychosomatic Medicine 1988, 50:477-483.

15. Adler N.E., Horowitz, M., Garcia, A., Moyer, A.: Additional validation of a scale to assess positive states of mind. Psychosomatic Medicine 1998, 60:26-32.

16. Trochim WMK: The Research Methods Knowledge Base. 2nd ed. Cincinnati, OH, Atomic Dog Publishing; 200I.

17. Katz J.N., Chang, L.C., Sangha, O., Fossel, A.H., Bates, D.W.: Can comorbidity be measured by questionnaire rather than medical record review? Medical Care 1996, 34:73-84.

18. Idler EL, Kasl S: Health perceptions and survival: do global evaluations of health status really predict mortality? Journal of Gerontology. |99|, 46:S55-65.

19. Idler E., Benyamini, Y.: Self-rated health and mortality: A review of twenty-seven community studies. Journal of Health and Social Behavior 1997, 38:21-36.

20. Long M.J., Marshall, B.S.: The relationship between self-assessed health status, mortality, service use, and cost in a managed care setting. Health Care Management Review 1999, 24:20-27.

21. Bath PA: Self-rated health as a risk factor for prescribed drug use and future health and social service use in older people. Journals of Gerontology Series A-Biological Sciences \& Medical Sciences. 1999, 54:M565-70.

22. Menec VH, Chipperfield JG, Perry RP: Self-perceptions of health a prospective analysis of mortality, control, and health. Journals of Gerontology Series B-Psychological Sciences \& Social Sciences. 1999, 54:85-93.

23. Mossey JM, Shapiro E: Self-rated health: a predictor of mortality among the elderly. American Journal of Public Health 1982, 72:800-808.

24. Derogatis Leonard R., Melisaratos Nick: The Brief Symptom Inventory: An introductory report. Psychological Medicine 1983, 13:595-605

25. Cochran C.D., Hale, W.D.: College student norms on the Brief Symptom Inventory. Journal of Clinical Psychology 1985, 4 I:777-779.

26. Derogatis Leonard R.: BSI: The Brief Symptom Inventory: Administration, Scoring, and Procedures Manual. Minneapolis, National Computer Systems, Inc.; 1993.

27. Owens JE, Taylor AG, Degood D: Complementary and alternative medicine and psychologic factors: toward an individual differences model of complementary and alternative medicine use and outcomes. Journal of Alternative \& Complementary Medicine 1999, 5:529-541.

28. Gottschalk A, Bauer MS, Whybrow PC: Evidence of chaotic mood variation in bipolar disorder.[comment]. Archives of General Psychiatry. 1995, 52:947-959.

29. Woyshville MJ, Lackamp JM, Eisengart JA, Gilliland JA: On the meaning and measurement of affective instability: clues from chaos theory. [erratum appears in Biol Psychiatry 1999 Apr 15;45(8):following 108 I]. Biological Psychiatry. 1999, 45:26I-269.

30. Cummins Robert $A$.: The subjective well-being of people caring for a family member with a severe disability at home: A review. Journal of Intellectual \& Developmental Disability 2001, 26:83-100.

31. Bath PA: Self-rated health as a risk factor for prescribed drug use and future health and social service use in older people. Journal of Gerontology, Series A 1999, 54:M565-70.

32. Menec V.H., Chipperfield, J.G., Perry, R.P.: Self-perceptions of health: a prospective analysis of mortality, control, and health. Journal of Gerontology Series B 1999, 54:P85-93.

33. Adams TB, Bezner JR, Drabbs ME, Zambarano RJ, Steinhardt MA: Conceptualization and measurement of the spiritual and 
psychological dimensions of wellness in a college population. Journal of American College Health. 2000, 48: 165- 173.

34. Krauss HH, Godfrey C, Kirk J, Eisenberg DM: Alternative health care: its use by individuals with physical disabilities. Archives of Physical Medicine \& Rehabilitation. 1998, 79:1440-I 447.

\section{Pre-publication history}

The pre-publication history for this paper can be accessed here:

http://www.biomedcentral.com/1472-6882/4/1/prepub

Publish with Bio Med Central and every scientist can read your work free of charge

"BioMed Central will be the most significant development for disseminating the results of biomedical research in our lifetime. "

Sir Paul Nurse, Cancer Research UK

Your research papers will be:

- available free of charge to the entire biomedical community

- peer reviewed and published immediately upon acceptance

- cited in PubMed and archived on PubMed Central

- yours - you keep the copyright

Submit your manuscript here:

http://www.biomedcentral.com/info/publishing_adv.asp 